\title{
Nudging Physician Prescription Decisions by Partitioning the Order Set: Results of a Vignette-Based Study
}

\author{
David Tannenbaum, $P h D^{7}$, Jason N. Doctor, PhD' , Stephen D. Persell, MD, MPH', \\ Mark W. Friedberg, MD, MPP4,5,8, Daniella Meeker, PhD 6 , Elisha M. Friesema, $B A^{3}$, \\ Noah J. Goldstein, $P h D^{7}$, Jeffrey A. Linder, $M D, M P H^{5,8}$, and Craig R. Fox, $P h D^{7}$
}

'UCLA Anderson School of Management, Los Angeles, CA, USA; ${ }^{2}$ Leonard D. Schaeffer Center for Health Policy and Economics, University of Southern California, Los Angeles, CA, USA; ${ }^{3}$ Division of General Internal Medicine and Geriatrics, Center for Healthcare Studies, Feinberg School of Medicine, Northwestern University, Chicago, IL, USA; ${ }^{4}$ RAND, Boston, MA, USA; ${ }^{5}$ Harvard Medical School, Boston, MA, USA; ${ }^{6}$ Department of Preventive Medicine, Keck School of Medicine, University of Southern California, Los Angeles, CA, USA; ${ }^{7}$ UCLA Anderson School of Management, Department of Psychology, David Geffen School of Medicine at UCLA, Los Angeles, CA, USA; ${ }^{8}$ Division of General Medicine and Primary Care, Brigham and Women's Hospital, Boston, MA, USA.

BACKGROUND: Healthcare professionals are rapidly adopting electronic health records (EHRs). Within EHRs, seemingly innocuous menu design configurations can influence provider decisions for better or worse.

OBJECTIVE: The purpose of this study was to examine whether the grouping of menu items systematically affects prescribing practices among primary care providers. PARTICIPANTS: We surveyed 166 primary care providers in a research network of practices in the greater Chicago area, of whom 84 responded (51\% response rate). Respondents and non-respondents were similar on all observable dimensions except that respondents were more likely to work in an academic setting.

DESIGN: The questionnaire consisted of seven clinical vignettes. Each vignette described typical signs and symptoms for acute respiratory infections, and providers chose treatments from a menu of options. For each vignette, providers were randomly assigned to one of two menu partitions. For antibiotic-inappropriate vignettes, the treatment menu either listed over-the-counter (OTC) medications individually while grouping prescriptions together, or displayed the reverse partition. For antibiotic-appropriate vignettes, the treatment menu either listed narrow-spectrum antibiotics individually while grouping broad-spectrum antibiotics, or displayed the reverse partition.

MAIN MEASURES: The main outcome was provider treatment choice. For antibiotic-inappropriate vignettes, we categorized responses as prescription drugs or OTC-only options. For antibiotic-appropriate vignettes, we categorized responses as broad- or narrow-spectrum antibiotics.

KEY RESULTS: Across vignettes, there was an 11.5 percentage point reduction in choosing aggressive treatment options (e.g., broad-spectrum antibiotics) when aggressive options were grouped compared to when those same options were listed individually (95\% CI: 2.9 to $20.1 \% ; p=.008$ ).

Electronic supplementary material The online version of this article (doi:10.1007/s11606-014-3051-2) contains supplementary material, which is available to authorized users.

Received April 17, 2014

Revised July 28, 2014

Accepted September 9, 2014

Published online November 14, 2014
CONCLUSIONS: Provider treatment choice appears to be influenced by the grouping of menu options, suggesting that the layout of EHR order sets is not an arbitrary exercise. The careful crafting of EHR order sets can serve as an important opportunity to improve patient care without constraining physicians' ability to prescribe what they believe is best for their patients.

KEY WORDS: Medical decision-making; Electronic health records; Physician decision support; Behavioral science.

J Gen Intern Med 30(3):298-304

DOI: $10.1007 / \mathrm{s} 11606-014-3051-2$

(C) Society of General Internal Medicine 2014

\section{BACKGROUND}

Electronic health records (EHRs) have been adopted by health providers at increasing rates in recent years based on the expectation that they improve the quality and efficiency of patient care. ${ }^{1-3}$ For example, EHRs often feature decision support systems that remind providers of guidelines for recommended care, and health information exchange may reduce duplicate testing. ${ }^{4}$ Beyond these commonly cited benefits, EHRs may offer another, overlooked opportunity for improvement. Through their design and layout, order sets (predetermined menus presented to an ordering provider within EHR applications) might influence physician treatment decisions, nudging physicians towards better patient care while preserving their full discretion to choose among all available options.

According to traditional economic models of decision-making, menu design can affect choices either by restricting what options are available to begin with, or by making some options particularly difficult to select (e.g., "burying" options deep within the order set). However, a robust literature in social psychology and behavioral economics has found that a variety 
of subtle changes to menu design can affect choices, even when the set of options is unrestricted and there are no search costs. ${ }^{5}$ For instance, merely labeling a policy option as the status quo generally increases its support, ${ }^{6,7}$ and the first option on a menu or ballot draws an excess share of choices. ${ }^{8,9}$ Thus, failure to consider the behavioral implications of EHR menu design may unintentionally bias provider decisions and undermine patient health.

One important aspect of any menu layout is the way in which the available options are grouped. A number of studies have determined that the partitioning (i.e., grouping) of options can strongly influence decisions, as people tend to be biased towards equal allocation of money or choices to each group of available options, regardless of how those options are partitioned. ${ }^{10-15}$ For instance, 401(k) investors allocate more money to stocks when the set of available funds includes a greater number of stockheavy investments, ${ }^{14}$ and consumers are more likely to diversify their wine purchases by types of grapes when wines are grouped by varietals (such as Chardonnays and Pinot Grigios) than when wines are grouped by winemaker region (such as California and Italian wines). ${ }^{10}$ While partitioning effects have been demonstrated among consumers and amateur investors, it remains to be seen whether the ad hoc grouping of an order list has a systematic effect on prescribing behavior by health care providers.

We investigated whether alternative partitions of order sets can influence provider decisions for treating acute respiratory infections (ARIs) and other common infections frequently treated with antibiotics. We hypothesized that health care providers would be biased towards choosing treatment options that are "unpacked" or listed individually, and biased away from choosing treatment options that are "packed" or listed as part of a group. We selected ARIs as a clinical scenario because they are common (comprising approximately $10 \%$ of all U.S. ambulatory care visits), and treatment decisions are frequently suboptimal in ways that threaten public health (the rate of inappropriate antibiotic prescription has been estimated at over $50 \%){ }^{16-21}$ If provider choices are, in fact, dependent on the manner in which response options are partitioned, this finding could inform the development of more effective clinical decision support systems.

\section{METHODS}

\section{Overview}

To assess the relationship between menu partition and treatment decisions, we surveyed practicing primary care providers using a series of ARI clinical vignettes in which we experimentally varied the grouping of treatment options. The Internal Review Boards of Northwestern University and the University of Southern California approved the study.

\section{Study Participants and Fielding}

We surveyed all 166 general internists, family physicians, and advanced practice nurses who provided adult primary care in an established research network of practices affiliated with an academic medical center in the greater Chicago area. This network included an academic faculty practice, several private practices, and a federally qualified community health center. We obtained data on each provider's professional degree (medical doctor, physician assistant, or advanced practice nurse) and practice setting (academic, private, or federally qualified health community center) from administrative records.

Participants received a mailed questionnaire that included a brief description of the study, the study questionnaire, and a $\$ 5$ bill that the recipient could keep regardless of whether they participated. Several weeks later, providers who had yet to participate were sent a reminder e-mail with a link to an online version of the questionnaire.

\section{Questionnaire Instrument and Design}

The questionnaire presented seven clinical vignettes to each provider. Three vignettes described ARIs not requiring antibiotics (acute non-bacterial pharyngitis, acute bronchitis, and acute nasopharyngitis) and four vignettes described antibioticappropriate infections (otitis media, urinary tract infection, acute sinusitis, and cellulitis). Following each vignette, providers chose treatments from a menu of options. For antibioticinappropriate vignettes, we divided treatment choices into over-the-counter (OTC) and prescription drugs, and providers could choose up to three treatments per vignette. For antibioticappropriate vignettes, we divided treatment choices into broadand narrow-spectrum antibiotics - treatments that act against a wider or narrower range of bacteria, respectively - and asked providers to choose one treatment per vignette. Guidelines from infectious disease societies generally recommend narrowspectrum antibiotics for the treatment of ARIs because use of broad-spectrum antibiotics more readily promotes the development of antibiotic-resistant bacteria. ${ }^{22,23}$ All vignettes are displayed in the Supplementary Materials available online.

For each vignette, we randomly assigned providers to menus containing one of two partition structures. For antibioticinappropriate vignettes, half of the providers received response options that listed OTC medications as individual options and grouped all prescription options into a single row of response options. The other half of providers received the reverse menu grouping (see Fig. 1a for an example). For the antibioticappropriate vignettes, half of the providers received response options that listed narrow-spectrum antibiotics individually and grouped all broad-spectrum antibiotics into a single row of response options, and the other half received the reverse menu grouping (see Fig. $1 \mathrm{~b}$ for an example). Thus, the study was a 2 (between-subjects: OTC medications listed individually vs. grouped) $\times 2$ (between-subjects: narrow-spectrum listed individually vs. grouped) $\times 7$ (within-subjects: medical vignette) mixed factorial design. As Fig. 1a and b illustrate, all available choices and information were held constant regardless of the menu partition.

To ensure that grouping rather than ordering of treatment options would drive any observed effects, we also randomized 
a

Antibiotic inappropriate vignette (Acute Bronchitis)

A 27-year-old woman with no known underlying lung disease presents with a 10-day history of cough that is productive of yellow nonbloody sputum. Her symptoms began with nasal congestion and a sore throat, but these initial symptoms resolved after a few days. Her remaining symptom is the cough which is less productive than it was several days ago. She denies any known sick contacts. Her cough does not occur in long fits, and there is no post-tussive emesis. On physical examination she is not in respiratory distress, afebrile, and has normal vital signs. Lung exam is normal.

OTC medications grouped:

Of the drug choices below, please indicate which drugs you would choose in treating this patient. You may select up to three options.

$$
\begin{aligned}
& \square \text { albuterol inhaler } \\
& \square \text { an antibiotic of your choice } \\
& \square \text { robitussin with codeine } \\
& \square \text { tessalon perles }
\end{aligned}
$$

Over-the-counter drugs:

$\square$ cough lozenge $\square$ cough spray $\square$ cough syrup

OTC medications listed individually:

Of the drug choices below, please indicate which drugs you would choose in treating this patient. You may select up to three options.

$$
\begin{aligned}
& \square \text { cough lozenge } \\
& \square \text { cough spray } \\
& \square \text { cough syrup }
\end{aligned}
$$

Prescription drugs:

$\square$ albuterol inhaler $\square$ an antibiotic of your choice $\quad \square$ robitussin with codeine $\quad \square$ tessalon merles

b Antibiotic appropriate vignette (Cellulitis)

A 40-year-old otherwise healthy man presents with recent onset of pain and redness involving the skin of his lower right leg and foot. Physical exam reveals a low-grade fever and fissures between the toes. There is tender edema and erythema extending from the dorsal surface of the right foot to the right pretibial area.

Narrow-spectrum medications grouped:

Which one of the following antibiotics would you choose to treat this patient?

$$
\begin{aligned}
& \square \text { amoxicillin-clavulanate } \\
& \square \text { azithromycin } \\
& \square \text { cefadroxil } \\
& \square \text { cefuroxime } \\
& \square \text { clindamycin } \\
& \square \text { moxifloxacin }
\end{aligned}
$$

Narrower-spectrum antibiotics:

$\square$ cephalexin $\square$ dicloxacillin $\square$ erythromycin $\square$ penicillin V

Narrow-spectrum medications listed individually:

Which one of the following antibiotics would you choose to treat this patient?

$$
\begin{aligned}
& \square \text { cephalexin } \\
& \square \text { dicloxacillin } \\
& \square \text { erythromycin } \\
& \square \text { penicillin V }
\end{aligned}
$$

Broader-spectrum antibiotics:

$\square$ amoxicillin-clavulanate $\square$ azithromycin $\quad \square$ cefadroxil $\square$ cefuroxime $\quad \square$ cefadroxil $\square$ cefuroxime $\quad \square$ clindamycin $\quad \square$ moxifloxacin 
Table 1. Sample Characteristics

\begin{tabular}{|c|c|c|c|}
\hline Characteristic & $\begin{array}{l}\text { Responders } \\
\% \text { (frequencies) }\end{array}$ & $\begin{array}{l}\text { Non-Responders } \\
\% \text { (frequencies) }\end{array}$ & $\begin{array}{l}\text { Responders different } \\
\text { from Non-Responders? }\end{array}$ \\
\hline Female sex & $(57 \%) 48 / 84$ & $(56 \%) 46 / 82$ & $\chi^{2}(1)=0.02, p=.892$ \\
\hline Age & mean $=45$ (range: $28-76)$ & N/A & \\
\hline $\begin{array}{l}\text { Professional Specialty } \\
\text { Internal medicine } \\
\text { Family medicine } \\
\text { Other }\end{array}$ & $\begin{array}{l}(85 \%) 71 / 84 \\
(12 \%) 10 / 84 \\
(4 \%) 3 / 84\end{array}$ & $\begin{array}{l}(80 \%) 66 / 82 \\
(12 \%) 10 / 82 \\
(7 \%) 6 / 82\end{array}$ & $\chi^{2}(2)=1.16, p=.560$ \\
\hline $\begin{array}{l}\text { Professional Degree } \\
\text { MD } \\
\text { PA } \\
\text { APN }\end{array}$ & $\begin{array}{l}(83 \%) 70 / 84 \\
(4 \%) 3 / 84 \\
(13 \%) 11 / 84\end{array}$ & $\begin{array}{l}(93 \%) 76 / 82 \\
(2 \%) 2 / 82 \\
(5 \%) 4 / 82\end{array}$ & $\chi^{2}(2)=3.69, p=.158$ \\
\hline $\begin{array}{l}\text { Practice Setting } \\
\text { Academic } \\
\text { Private } \\
\text { FQHCC }\end{array}$ & $\begin{array}{l}(35 \%) 29 / 84 \\
(20 \%) 17 / 84 \\
(45 \%) 38 / 84\end{array}$ & $\begin{array}{l}(10 \%) 8 / 82 \\
(28 \%) 23 / 82 \\
(62 \%) 51 / 82\end{array}$ & $\chi^{2}(2)=14.70, p=.001$ \\
\hline Years practicing & mean $=15$ (range: $0-43)$ & N/A & \\
\hline Hours per week providing patient care & mean $=28$ (range: $2-50)$ & N/A & \\
\hline
\end{tabular}

Notes: ${ }^{*}$ Responders were also not significantly different from non-responders when comparing the proportion of MDs to non-MDs, $\chi^{2}(1)=3.42, p=0.064$

the order of questionnaire items on three dimensions: whether the questionnaire began with antibiotic-appropriate or antibiotic-inappropriate vignettes, the order of vignettes within these categories, and the positioning of the grouped menu items (first or last option in the menu). 8,9

Finally, we asked for respondents' age, gender, professional specialty (internal medicine, family medicine, or other), number of years of practice, and hours per week spent providing patient care.

\section{Analysis}

Provider treatment choice was the primary outcome measure. For antibiotic-inappropriate vignettes, we categorized responses as "aggressive treatment" when one or more prescription drugs were recommended $(0=$ OTC-only options, $1=$ prescription drugs). For antibiotic-appropriate vignettes, we categorized responses as aggressive treatment when broad-spectrum antibiotics were recommended $(0=$ narrow-spectrum antibiotics, $1=$ broad-spectrum antibiotics). In a small number of cases, participants wrote in treatments other than the options provided. We categorized these responses as aggressive or nonaggressive according to same criteria; omitting the handwritten responses from the analysis yielded similar results to those reported below (see Table 1 in the online Supplementary Materials for details). For three of the questionnaires, there was a misprint for the Acute Bronchitis vignette, so we excluded these responses from the main analysis.

We conducted all analyses using logistic regression, with standard errors clustered by provider and patient vignettes

Table 2. Percentage choosing aggressive treatment options as a function of menu partition

\begin{tabular}{|c|c|c|c|c|c|c|}
\hline & \multirow{2}{*}{$\begin{array}{l}\text { Aggressive } \\
\text { treatment options } \\
\text { listed individually }\end{array}$} & \multirow{2}{*}{$\begin{array}{l}\text { Aggressive } \\
\text { treatment options } \\
\text { grouped together }\end{array}$} & \multicolumn{2}{|c|}{$\begin{array}{l}\text { Model I: without adjusting } \\
\text { for provider demographic } \\
\text { characteristics }\end{array}$} & \multicolumn{2}{|c|}{$\begin{array}{l}\text { Model II: adjusting for } \\
\text { provider demographic } \\
\text { characteristics }\end{array}$} \\
\hline & & & $\begin{array}{l}\text { Difference } \\
{[95 \% \mathrm{CI}]}\end{array}$ & $p$-value & $\begin{array}{l}\text { Difference } \\
\text { [95 \% CI] }\end{array}$ & $p$-value \\
\hline All results combined & 43.7 & 32.2 & $11.5[2.9,20.1]$ & .008 & $12.0[4.4,19.5]$ & .002 \\
\hline $\begin{array}{l}\text { Antibiotic-inappropriate vignettes } \\
\text { (\% choosing only prescription drugs) }\end{array}$ & $(n=39)$ & $(n=45)$ & & & & \\
\hline Acute non-strep & 25.6 & 13.3 & $12.3[-4.6,29.2]$ & .154 & $6.3[-13.1,25.6]$ & .526 \\
\hline Acute bronchitis & 74.3 & 64.4 & $9.8[-10.3,30.0]$ & .338 & $17.3[-3.7,38.4]$ & .106 \\
\hline Acute nasopharyngitis & 5.1 & 4.4 & $0.7[-8.5,9.9]$ & .884 & $1.5[-9.4,12.3]$ & .790 \\
\hline Combined results & 34.4 & 26.8 & $7.6[-2.2,17.3]$ & .127 & $8.5[-1.6,18.6]$ & .098 \\
\hline $\begin{array}{l}\text { Antibiotic-appropriate vignettes } \\
\text { (\% choosing broad-spectrum) }\end{array}$ & $(n=41)$ & $(n=43)$ & & & & \\
\hline Otitis media & 36.6 & 16.7 & $19.9[1.4,38.5]$ & .035 & $22.2[2.8,41.6]$ & .025 \\
\hline Urinary tract infection & 53.7 & 43.9 & $9.8[-11.8,31.3]$ & .375 & $7.6[-14.4,29.6]$ & .500 \\
\hline Sinusitis & 53.7 & 54.8 & $-1.1[-22.5,20.3]$ & .920 & $-0.1[-21.5,21.4]$ & .996 \\
\hline Cellulitis & 58.5 & 29.3 & $29.3[8.7,49.8]$ & .005 & $31.0[10.6,51.4]$ & .003 \\
\hline Combined results & 50.6 & 36.2 & $14.4[1.2,27.6]$ & .032 & $14.7[2.1,27.4]$ & .022 \\
\hline
\end{tabular}

Note: All significance tests are two-tailed 


\section{Aggressive treatments Aggressive treatments listed individually grouped together}
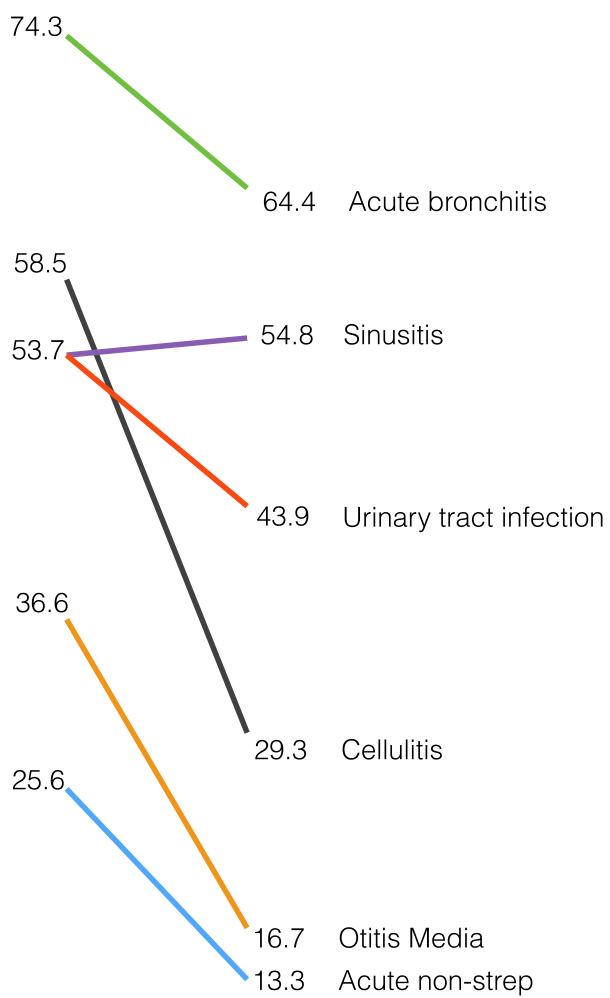

5.1 4.4 Acute nasopharyngitis

Fig. 2. Percentage of providers choosing aggressive treatment options (i.e., prescription drugs for antibiotic-inappropriate vignettes and broad-spectrum antibiotics for antibiotic-appropriate vignettes) as a function of menu partition

treated as fixed effects. ${ }^{24}$ We report the results both with and without the inclusion of provider demographic covariates (age, gender, professional specialty, number of years of practice, and hours per week spent providing patient care). Statistical analyses were conducted using Stata/IC software (version 12.1).

\section{RESULTS}

Of 166 providers surveyed, 84 completed the questionnaire (51\% response rate). Demographic characteristics of our sample are provided in Table 1. These figures closely match the demographics of the physicians in our sample who chose not to participate, with the exception that survey responders were more likely than non-responders to work in an academic setting ( $35 \%$ vs. $10 \% ; p<0.001)$. A total of 68 questionnaires were completed by mail and 16 were completed online; statistically controlling for response modality did not meaningfully affect the results reported below.

Results of our analysis are summarized in Table 2 and visually displayed in Fig. 2. Pooling the results across all vignettes, we observed an 11.5 percentage reduction in choice of aggressive treatment options (i.e., prescription drugs for antibiotic-inappropriate vignettes or broad-spectrum antibiotics for antibiotic-appropriate vignettes) when aggressive options were grouped compared to when those same options were listed individually ( $95 \%$ confidence interval, 2.9 to $20.1 \% ; p<.01)$. Adjusting for provider characteristics returned an estimated 12.0 percentage point reduction in aggressive treatment options (95\% CI, 4.4 to $19.5 \% ; p<0.01$ ).

The magnitude of this effect varied from vignette to vignette, with larger reductions in broad-spectrum antibiotic use for antibiotic-appropriate vignettes (an average 14.4 percentage point reduction) than prescription drug use for antibioticinappropriate vignettes (an average 7.6 percentage point reduction). The direction of the partitioning effect was consistent across six of the seven vignettes.

\section{DISCUSSION}

We found in a set of clinical vignettes that the grouping of menu options had a systematic and statistically significant influence on prescription choices by experienced primary care providers. Across patient cases, there was roughly an 11 percentage point reduction in choice of aggressive treatment options when aggressive options were grouped into a single response category compared to when they were listed individually. Assuming that these findings extend to actual clinical decision-making, the partitioning of menu items represents an effective technique for nudging more appropriate provider behavior without limiting their freedom of choice.

Our results suggest that EHR menus could promote judicious prescription practices by maximizing the number of appropriate medications (and listing them as distinct response options) while minimizing the number of response options for inappropriate medications (by grouping them together). Doing so may promote appropriate physician practices for several reasons. Individually listing or "unpacking" appropriate choices can increase their salience, ${ }^{24}$ encouraging providers to consider the benefits of these options more intently and at greater length - which will generally increase their likelihood of being selected. Second, unpacking only appropriate options may signal to providers that such options represent the most common or appropriate prescription practices, which may encourage adherence to these social norms. ${ }^{15}$

One attractive feature of using menu partitions to nudge appropriate prescription practices is that this approach imposes no additional costs on physicians who have a genuine preference or legitimate reason for prescribing more aggressive treatments to their patients. ${ }^{26,27}$ Menu partitioning also represents a relatively scalable intervention, as it is possible in multiple EHRs to generate and implement order sets with different menu groupings. ${ }^{28}$ Other forms of choice architecture, such as the strategic selection of default treatment options, ${ }^{29,30}$ can also supplement menu partitioning. 
Naturally, our study has several limitations. First, our sample was restricted to a single provider population, so it is unclear how our results would generalize to other clinical settings. The overrepresentation of academic providers in our survey may have introduced a response bias. For instance, if academic physicians are more aware of guidelines than other physicians, this response bias could reduce the observed effect of partitioning. A fruitful avenue for future research would be to examine whether menu partitioning effects generalize to other provider populations and whether subgroups of providers are particularly responsive to the grouping of menu items. Second, choices in the questionnaire were hypothetical. Although previous research has linked choices in vignette surveys to actual prescription practices, ${ }^{31}$ other factors that come to bear on real prescription choices (e.g., patient demand) could affect the magnitude of these partitioning effects. Third, the vignette response options were not displayed on a computer or other facsimile of an EHR display. Current and future EHR interfaces may contain design elements other than the menu partition that influence the impact of partitioning on provider choice. Fourth, we surveyed providers at a single point in time. It is unclear whether partitioning menu options will result in momentary or long-term changes in prescription behavior.

The present results have important and testable implications for the design of EHR decision support systems. EHRs are becoming increasingly prevalent in medical settings, and the current findings suggest that the presentation of EHR order sets should not be viewed as an arbitrary exercise. The careful design of EHR order set presentation can serve as an important opportunity to improve patient care without constraining physicians' ability to prescribe what they believe is best for their patients. Conversely, failure to carefully consider the design of EHR order sets may result in unintended influences on provider behavior that have the potential to undermine patient care and public health. ${ }^{32}$

Funders: This research was supported by a grant from the National Institutes of Health/National Institute on Aging (Use of Behavioral Economics to Improve Treatment of Acute Respiratory Infections, PI $J$ Doctor, Grant\#: RC4 AG039115).

Contributors: None.

\section{Prior Presentations: None.}

Disclosure of Potential Conflicts of Interest: JND and DM are employed by the University of Southern California, who received the aforementioned grant from the National Institute on Aging, which provided support for this research. Work on this research by DM and MWF was supported by a subcontract to RAND from the University of Southern California as part of the aforementioned grant. Work on this research by DT, CRF, and NJG was supported by a subcontract to UCLA from the University of Southern California as part of the aforementioned grant. Work on this research by SDP and EMF was supported by a subcontract to Northwestern University from the University of Southern California as part of the aforementioned grant. Work on this research by JAL was supported by a subcontract to Brigham and Women's Hospital as part of the aforementioned grant.

Corresponding Author: David Tannenbaum, PhD; UCLA Anderson School of Management, 110 Westwood Plaza D-501, Los Angeles, CA 90095, USA (e-mail: david.tannenbaum@anderson.ucla.edu).

\section{REFERENCES}

1. Hsiao CJ, Jha AK, King J, Patel V, Furukawa MF, Mostashari F. Officebased physicians are responding to incentives and assistance by adopting and using electronic health records. Health Aff. 2013;32(8): 1470-7.

2. Bates DW, Gawande AA. Improving safety with information technology. N Engl J Med. 2003;348(25):2526-2534.

3. Jones SS, Rudin RS, Perry T, Shekelle PG. Health information technology: an updated systematic review with a focus on meaningful use. Ann Intern Med. 2014;160(1):48-54.

4. Schiff GD, Bates DW. Can Electronic Clinical Documentation Help Prevent Diagnostic Errors? N Engl J Med. 2010;362(12):10661069.

5. Slovic P. The construction of preference. Amer Psych. 1995;50(5):364-371.

6. Samuelson W, Zeckhauser R. Status quo bias in decision making. J Risk Uncertainty. 1988;1(1):7-59.

7. Moshinsky A, Bar-Hillel M. Loss Aversion and Status Quo Label Bias. Social Cognition. 2010;28(2):191-204.

8. Koppell JG, Steen JA. The Effects of Ballot Position on Election Outcomes. J Politics. 2004;66(1):267-281.

9. Dayan E, Bar-Hillel, M. Nudge to nobesity II: Menu positions influence food orders. Judg Decis Making; 6(4):333-342.

10. Fox CR, Ratner RK, Lieb DS. How subjective grouping of options influences choice and allocation: diversification bias and the phenomenon of partition dependence. J Exp Psychol Gen. 2005; 134(4):538-551.

11. Fox CR, Clemen RT. Subjective probability assessment in decision analysis: Partition dependence and bias toward the ignorance prior. Manage Sci. 2005;51(9):1417-1432.

12. Sonnemann U, Camerer CF, Fox CR, Langer T. Psychological biases affect economic market prices. Proc Natl Acad Sci USA, 110 (29): 11779-11784.

13. Redelmeier DA, Koehler DJ, Liberman V, Tversky A. Probability judgment in medicine: discounting unspecified possibilities. Med Decis Making. 1995; 15(3):227-230.

14. Benartzi S, Thaler RH. Naive diversification strategies in defined contribution saving plans. Am Econ Rev. 2001;91(1):79-98.

15. Tannenbaum D, Fox CR, Goldstein NJ. Partitioning menu items to nudge single-item choice. Paper presented at: 34th Annual Meeting for the Society for Judgment and Decision Making; November 16, 2013; Toronto, ON.

16. Grijalva CG, Nuorti JP, Griffin MR. Antibiotic prescription rates for acute respiratory tract infections in US ambulatory settings. JAMA. 2009;302:758-766.

17. Gonzales R, Malone DC, Maselli JH, Sande MA. Excessive antibiotic use for acute respiratory infections in the United States. Clin Infect Dis. 2001;33:757-762.

18. Centers for Disease Control and Prevention. Antibiotic Resistance Threats in the United States, 2013. 2013; http://www.cdc.gov/drugresistance/ threat-report-2013/.

19. Fendrick AM, Monto AS, Nightengale B, Sarnes M. The economic burden of non-influenza-related viral respiratory tract infection in the United States. Arch Intern Med. 2003;163(4):487-494.

20. Barnett ML, Linder JA. Antibiotic prescribing to adults with sore throat in the United States, 1997-2010. JAMA Intern Med. 2014;174(1):138-140.

21. Barnett ML, Linder JA. Antibiotic prescribing for adults with acute bronchitis in the United States, 1996-2010. JAMA. 2014;311(19):20202022.

22. Cooper RJ, Hoffman JR, Bartlett JG, et al. Principles of appropriate antibiotic use for acute pharyngitis in adults: background. Ann Intern Med. 2001;134(6):509-17.

23. Hickner JM, Bartlett JG, Besser RE, et al. Principles of appropriate antibiotic use for acute rhinosinusitis in adults: background. Ann Intern Med. 2001;134(6):498-505.

24. Freedman DA. On the so-called "Huber sandwich estimator" and "robust standard errors.”. Am Stat. 2006;60(4):299-302. 
25. Johnson EJ, Häubl G, Keinan A. Aspects of endowment: a query theory of value construction. J Exp Psychol Learn. 2007;33(3):461-474.

26. Thaler RH, Sunstein CR. Libertarian paternalism. Am Econ Rev. 2003;93(2):175-179.

27. Camerer C, Issacharoff S, Loewenstein G, O'Donoghue T, Rabin M. Regulation for conservatives: behavioral economics and the case for "Asymmetric Paternalism". Univ Penn Law Rev. 2003;151(3):12111254.

28. Persell SD, Friedberg MW, Meeker D, et al. Use of behavioral economics and social psychology to improve treatment of acute respiratory infections (BEARI): rationale and design of a cluster randomized controlled trial
[1RC4AG039115-01] — study protocol and baseline practice and provider characteristics. BMC Infect Dis. 2013;13:290.

29. Johnson EJ, Goldstein D. Do defaults save lives? Science. 2003;5649(302): 1338-1339.

30. Halpern SD, Ubel PA, Asch DA. Harnessing the power of default options to improve health care. N Engl J Med. 2007;357(13):1340-4.

31. Cutler D, Skinner J, Stern AD, Wennberg D. Physician beliefs and patient preferences: A new look at regional variation in spending. Unpublished manuscript, Harvard University, 2013.

32. Ansher C, Ariely D, Nagler A, Rudd M, Schwartz J, Shah A. Better medicine by default. Med Decis Making. 2013;34(2):147-158. 